\title{
A memória do mundo e a confiança em Yves Bonnefoy
}

\author{
Pablo Simpson \\ Universidade Estadual Paulista - São José do Rio Preto
}

Faço-o confiante que a memória, Ensinando essas palavras simples aos que buscam

Fazer que haja sentido, apesar do enigma, Os fará decifrar, em grandes páginas, Teu nome uno e múltiplo (...)

Yves Bonnefoy, As Pranchas curvas ${ }^{1}$

$\mathrm{M}$ uito embora a poesia de Yves Bonnefoy tenha sido quase integralmente traduzida no Brasil por Mário Laranjeira em 1998 - há pouco mais de 15 anos, portanto - e apesar da enorme abrangência de interesses que a obra de Bonnefoy recobre - ele foi tradutor e crítico de Shakespeare, escreveu ensaios sobre Baudelaire, Mallarmé, Rimbaud, sobre tradução, artes visuais, música, etc. — apesar disso, sua circulação em nosso ambiente de pesquisas literárias e estudos sobre a poesia permanece incipiente. Há talvez algumas hipóteses para isso: o nosso menor acesso atual à poesia francesa, mas também uma certa imagem da poesia moderna e das paisagens e temas que essa poesia percorre, de forma mais consistente, desde as vanguardas - a cidade, os seus habitantes

${ }^{1}$ BONNEFOY, 2001, p. 78: “Je le fais, confiant que la mémoire,/ Enseignant ses mots simples à ceux qui cherchent/ À faire être le sens malgré l'énigme,/ Leur fera déchiffrer, sur ses grandes pages,/ Ton non un et multiple (...)". Todas as traduções são de minha autoria. 
e misérias, a ironia, o jogo com as palavras, o movimento ágil do olhar e do "eu" - aos quais a poesia de Yves Bonnefoy vai renunciar.Mas eu talvez esteja mensurando mal a circulação de sua obra, sabendo que há um modo de difusão das obras literárias entre poetas e críticos que pode permanecer um tanto quanto invisível.

De todo modo, é possível dizer, sem hesitar, que a obra de Yves Bonnefoy é central para o panorama poético e crítico da literatura francesa da segunda metade do século XX. As inúmeras traduções e a enorme bibliografia crítica a ela consagradas demonstram a sua vitalidade poética e crítica. Se há, aliás, algo a partir do qual seja possível começar esta apresentação é justamente por essa dualidade: poesia e crítica. Ela estará no centro de minha apresentação, que confrontará, com vistas a uma reflexão sobre o lugar da memória e do esquecimento, alguns poemas do livro Les Planches courbes de 2001, a partir de um ensaio crítico intitulado "Sous l'horizon du langage" publicado em livro homônimo em 2002.

Tal dualidade vem desde a publicação quase simultânea do livro de ensaios intitulado L'Improbable (1959), em que havia vários estudos teóricos sobre a poesia francesa como, por exemplo, "La poésie française et le principe d'identité" ou "L'acte et le lieu de la poésie",e do aclamado livro de poemas Du Mouvement et de l'immobilité de Douve (1953). Dualidade no sentido de que a produção poética de Yves Bonnefoy se deixa acompanhar por uma reflexão teórica constante, múltipla, exigente.Maurice Blanchot escreveu dois ensaios sobre ela já em 1959: "Le grand refus"e "Comment découvrir l'obscur?", ambos publicados na Nouvelle revue française. Nesse período, Bonnefoy estaria preocupado com a noção de morte que assinalou em Baudelaire - morte igualmente presente nos poemas de Douve - e com a noção de presença. Gostaria de aprofundar esta última rapidamente, embora ela já esteja bastante mapeada por 
sua crítica. A presença seria uma espécie de "mundo sensível" - expressão que herdará do poeta Pierre Jean Jouve - e que indicaria a sua distância, assim como a de vários poetas do pós-guerra, com relação ao surrealismo. Para Bonnefoy, que escreveu livros, de algum modo, surrealistas como Le cœurespace (1945), recorrer ao imaginário, que foi o lugar de uma crítica à sociedade por parte do grupo de André Breton, se tornaria,nos anos 1950,o mesmo que afastar-se de um mundo real, de uma "realidade rugosa" - expressão de Rimbaud. Passaria a identificar um idealismo na poética surrealista ao qual responderia com essa noção de presença.

Trata-se de uma noção difícil, que investiguei trazendo-a para junto de uma reflexão sobre o tempo: para essa temporalidade que advém da angústia do ser-para-a-morte, para usar um pouco do vocabulário heideggeriano, de que se serviu Bonnefoy e que esteve presente em vários outros poetas, críticos e filósofos do período via Sartre ou Jean Wahl, que foi professor de Bonnefoy e leitor atento de Heidegger. Há, aliás, muito de uma reflexão existencial, às vezes com certa dimensão religiosa, nos túmulos, pedras e vozes que surgirão nos primeiros livros de poemas de Bonnefoy, como na imagem da "abóboda furtiva" que apareceria no livro Pierre écrite (1965) como signo dessa "presença":

O présence,

Sous ta voûte furtive accueille-nous

Pour une fête obscure.

[Ó presença

Sob tua abóboda furtiva acolhe-nos

Para uma festa obscura. $]^{2}$

${ }^{2}$ BONNEFOY, 1982, p. 232. 
A presença evocaria também um mundo natural em seus aspectos fugitivos - como o túmulo vazio ${ }^{3}$ - , cheios de sensações e equívocos e, por isso, misteriosos, obscuros. Daí o interesse coetâneo de Bonnefoy pela pintura de Piero Della Francesca, Fra Angélico, Paolo Uccello, uma vez preocupado com um tempo da existência, do instante, face à adoção da perspectiva e da simetria na pintura do Renascimento. No ensaio "Le temps et l'intemporel dans la peinture du Quattrocento", por exemplo,se deteria na série A profanação da hóstia ou O milagre da hóstia profanada de Paolo Ucello (1465-69, Galleria Nazionale delle Marche, Urbino). Menciono essa série porque ela foi referida no romance Nadja, de André Breton. Uccello esteve, igualmente, no centro das preocupações de Philippe Soupault, poeta surrealista, que foi a Urbino para ver pessoalmente esse milagre da hóstia, em 1925, e lhe dedicou um estudo para a coleção Maîtres de l'art ancien (1929). Para Soupault, a suposta irrealidade dos quadros de Uccello, a rapidez dos gestos do pintor (quase um automatismo) fariam dele um precursor do surrealismo ${ }^{4}$.

Bonnefoy, que compartilharia do mesmo entusiasmo com relação ao pintor italiano - e, eu diria, com relação a várias das escolhas poéticas e artísticas do surrealismo - observaria nessa série, entretanto,algo bem diferente. Cito o trecho em que ele descreve a Profanação:

Se a Profanação "é" do tempo, é porque ela se angustia, no tremor dos dedos e na fixidez dos olhares, com um futuro iminente e com a sua virtualidade trágica, é porque ela diz o ser próprio dessa rede de projetos e de inquietações que chamamos de nosso tempo. ${ }^{5}$

\footnotetext{
${ }^{3}$ BONNEFOY, 1980, p. 19: "Mais le couvercle est ôté, la tombe vide. Ó pure joie, qui prend soudain le coeur!"

${ }^{4}$ RUSSO, 2007, p. 100.

${ }^{5}$ BONNEFOY, 1980, p. 66: "Si la Profanation "est" du temps, c'est qu'elle s'angoisse, dans le tremblé des doigts ou la fixité des regards, d'un avenir
} 
Para Bonnefoy, Uccello traria em seus personagens a iminência da morte numa espécie de duração sugerida por seus gestos, pela suspensão do tempo da ação que seria angústia, projeto. A pintura preservaria uma profundidade do movimento, uma espessura de ambiguidades e contradições. É o mesmo movimento que o poeta trará nos gestos da personagem de Du mouvement et de l'immobilité de Douve. Cito um fragmento desse livro importante. Para além da atenção, no poema, a um instante efêmero do presente, à imediatez dos olhos que se corrompem, o "eu" questionaria o próprio estatuto da representação (ou da imagem, por assim dizer, da imagem poética: lembrando que a imagem é constitutiva da reflexão surrealista) a partir de uma duplicidade entre o rosto da personagem e a palavra rosto:

Ton visage ce soir éclairé par la terre,

Mais je vois tes yeux se corrompre

Et le mot visage n'a plus de sens.

[Teu rosto esta noite iluminado pela terra,

Mas vejo teus olhos corromperem-se

E a palavra rosto não tem mais sentido. $]^{6}$

Destaco essa duplicidade para chegar a um último desdobramento da noção de presença. Para Bonnefoy, a presença seria também um modo de combater o esquecimento a que estão sujeitas tanto as palavras - "la parole est déjà l'oubli" diria em $L^{\prime}$ Improbable ${ }^{7}$ - quanto as diversas mediações de que

imminent et de sa virtualité tragique, c'est qu'elle dit l'être propre de ce réseau de projets et d'inquiétudes que nous nommons notre temps." ${ }^{6}$ BONNEFOY, 1982, p. 57.

${ }^{7}$ BONNEFOY, 1980, p. 126. 
dispomos: lembro, aliás, que Hegel está na epígrafe do livro de poemas de 1953. Caberia à verdadeira poesia, assim, redescobrir um modo de acesso a um mundo perdido ou guardar memória de seus aspectos mais fugitivos ${ }^{8}$.

Há, portanto, algo de um dever ético ou de uma responsabilidade em restituir o acesso a esse mundo, ao concreto, ao sensível, e que faz com que a poesia de Bonnefoy adquira, muitas vezes, um ar grave, solene - tanto mais pelo uso, com relativa frequência, de versos decassílabos e alexandrinos. Do ponto de vista crítico, a noção de presença lhe permitiria separar, além disso, duas vias para a poesia francesa. Uma delas se abriria ao sensível, ao ser; a outra se fecharia conceitualmente, seria autorreferencial. Num ensaio sobre Paul Valéry, chegaria a afirmar que este "se compraz num mundo de essências onde nada nasce nem morre" ${ }^{\prime \prime}$.

O que gostaria de reter desse aspecto da noção de presença para a leitura do livro Les Planches courbes é essa dimensão da memória/esquecimento. Ela estará nos poemas e na reflexão crítica que lhes é contemporânea, como numa espécie de continuidade entre ambas. Há várias dimensões da memória presentes em Les Planches courbes, memória de uma poesia que se voltará ao passado: é o poeta que retornará à casa natal, na série intitulada "La maison natale", com a inquietação do ubi sunt, "onde estão", procurando nos móveis e espelhos a presença daqueles que se foram. Para encontrar o pai sentado nojardim. Cito esse trecho, queé a primeira menção em toda a sua obra à figura paterna:

Je me souviens, c'était un matin, l'été,

La fenêtre était ouverte, je m'approchais,

${ }^{8}$ BONNEFOY, 1980, p. 131: "Le moindre objet, l'être le plus fugitif, par le bien qu'ils feront, réveilleront l'espoir d'un bien absolu". ${ }^{9}$ BONNEFOY, 1980, p. 101: “Il se complaît dans un monde d'essences où rien ne naît ni ne meurt". 
J'apercevais mon père au fond du jardin.

Il était immobile, il regardait

Où, quoi, je ne savais, au-dehors de tout,

Vôuté comme il était déjà mais redressant

Son regard vers l'inaccompli ou l'impossible.

Il avait déposé la pioche, la bêche,

L'air était frais ce matin-là du monde,

Mais impénétrable est la fraîcheur même, et cruel

Le souvenir des matins de l'enfance.

Qui était-il, qui avait-il été dans la lumière,

Je ne le savais pas, je ne sais encore.

[Eu me lembro, era uma manhã, o verão,

A janela entreaberta, aproximava-me,

Percebia meu pai no fundo do jardim.

Imóvel, ele observava

Onde, o quê, eu não sabia, fora de tudo,

Curvado como já estava, mas reerguendo

O olhar ao inacabado ou impossível.

Tinha largado o alvião, a enxada,

O ar estava fresco na manhã do mundo,

Mas impenetrável esse frescor, e cruel

A lembrança das manhãs da infância.

Quem era ele, quem tinha sido na luz,

Eu não sabia, eu não sei ainda. ${ }^{10}$

Uma outra dimensão da memória estará na lembrança do encontro amoroso, em poemas tão belos como os da série "La pluie d'été" / "A chuva de verão", oscilando entre o passado da ação e o encontro presente das mãos que se juntam — com verbos no presente e no imperativo. Cito um desses momentos:

Une hâte mystérieuse nous appelait.

Nous sommes entrés, nous avons ouvert

${ }^{10}$ BONNEFOY, 2001, p. 90. 
Les volets, nous avons reconnu la table, l'âtre, Le lit; l'étoile grandissait à la croisée, Nous entendions la voix qui veut qu l'on aime Au plus haut de l'été

Comme jouent les dauphins dans leur eau sans rive.

Dormons, ne nous sachant. Sein contre sein, Souffles mêlés, main dans la main sans rêves.

[Uma pressa misteriosa nos chamava.

Nós entramos, nós abrimos

Os postigos, reconhecemos a mesa, a lareira, A cama; a estrela se alargava na vidraça, Ouvíamos a voz que deseja que amemos No mais alto verão,

Como brincam os golfinhos em sua água sem margens.

Durmamos, não sabendo de nós. Seio contra seio, Fôlegos mesclados, mão na mão sem sonhos. $]^{11}$

A lembrança, como se vê, é constitutiva dessa voz lírica.

Mas há outros dois caminhos dessa memória aos quais gostaria de apontar, e que se relacionariam de modo mais evidente com a reflexão sobre a presença e o esquecimento. $\mathrm{O}$ primeiro deles está nos vários mitos presentes em Les Planches courbes, muitos deles relacionados com a infância. São mitos como os de Zêuxis, Mársias, Ceres, Prosérpina, Psiquê, Caronte. Talvez pudéssemos observar neles o que Yves Bonnefoy definiu no Dictionnaire des mythologies que coordenou para a editora Flammarion em 1999: mitos como "um dos aspectos de nossa relação com nós-mesmos"12.

Um deles, o de Ceres, estará em dois momentos de Les Planches courbes: na primeira parte, "La pluie d'été", e em "La

${ }^{11}$ BONNEFOY, 2001, p. 17.

${ }^{12}$ BONNEFOY (org.), 1999, p.XIV. 
maison natale". De forma resumida, diz respeito ao rapto de sua filha Coré (Korê Dêmêtros) por Hades. Coré colhia violetas e lírios quando o rei dos infernos decidiu levá-la consigo e torná-la sua esposa, geralmente designada como Perséfone. A esse rapto segue a busca de sua mãe por toda a terra. É o momento em que bate à porta de uma cabana, conforme descrita na quinta parte das Metamorfoses de Ovídio e representada na tela de Adam Elsheimer que está no Museu do Prado em Madri, e sobre a qual há um estudo de Yves Bonnefoy intitulado "Elsheimer et les seins", publicado em Le Nuage rouge: essais sur la poétique (1977). Ceres, recebida por uma velha, a quem pede algo para beber, no instante em que traz o cântaro aos lábios, depara com um menino que ri de sua avidez. Ela, então, a mesma capaz de amar Prosérpina, é aquela que transforma essa outra criança num lagarto. Cito um trecho do poema, que está na mesma série de poemas que fazem menção à figura do pai, para mostrar como essa recuperação da memória - desses momentos de plenitude evocados por ela - está perpassada pela referência aos mitos, e, neste caso, por um mito particular, capaz de situar, ao mesmo tempo, um lugar da perda, da morte, e outro da esperança do reencontro.

Je comprends maintenant que ce fût Cérès

Qui me parut, de nuit, chercher refuge

Quand on frappait à la porte, et dehors,

C'était d'un coup sa beauté, sa lumière

Et son désir aussi, son besoin de boire

Avidement au bol de l'espérance (...)

[Compreendo, agora, o que foi Ceres

Que surgiu, na noite, para buscar refúgio

Quando batiam na porta, e fora,

Era, súbito, sua beleza, sua luz

E também seu desejo, a necessidade de beber

Avidamente na jarra da esperança $(. .).]^{13}$

${ }^{13}$ BONNEFOY, 2001, p. 97. 
O mito surge aqui, portanto, para explicitar uma dimensão da memória do eu. Ela está posta sob o signo da reparação da angústia. Ceres, noutros momentos do poema, lembraria dos instantes em que brincava com a filha nos campos de trigo. São imagens da dança, da música, do riso, do amor, que estarão ao longo de todo o livro, sem que resultem, no entanto, numa espécie de idealidade e pureza moral do "eu". Trata-se de um passado espectral, e que pede justiça. De um retorno ao passado como modo de apaziguá-lo através de sua reescrita.

Nesse sentido, a memória se situa aqui menos a partir de um lugar perdido do que reconquistado. Se o esquecimento havia se imposto, até então, como uma das questões principais à obra poética de Yves Bonnefoy, esquecimento que "violenta o texto, escava uma falha e imprime sua presença"14_ " "l'oubli, l'oubli avide", no poema "La maison natale"15 — a poesia se tornaria o lugar possível da lembrança. Ela traz um "eu" que assente às próprias recordações: confiança na palavra poética, no "sim", no consentimento, na paz, em meio a um século caracterizado, e ao qual responderia Bonnefoy num livro mais recente, intitulado Le siècle où la parole a été victime (2010), pelas noções de crise e suspeita. É uma confiança que retoma, de certo modo, o que Paul Ricœur explicitou como uma "política da justa memória", perpassada pela culpabilidade (memória da repetição, impedida) e pelo perdão, em busca do que chamou de uma "mémoire heureuse" ou "équitable"16.

${ }^{14}$ LEUWERS, 1988, p. 25.

${ }^{15}$ BONNEFOY, 2001, p. 91.

16 RICOEUR, 2000. Dividido em três partes, a primeira delas consagrada aos fenômenos mnemônicos, a segunda, à história e a terceira, culminando numa meditação sobre o esquecimento, o estudo de Paul Ricoeur se volta ao que caracterizaria como uma "política da justa memória", perpassada pela culpabilidade (memória da repetição, impedida) e pelo perdão, em busca do que chamou de uma "mémoire heureuse" ou "équitable". 
Com isso, chego ao segundo caminho ao qual gostaria de apontar brevemente. A memória, diria Bonnefoy - e como vimos com a noção de presença — será também aquela "dos referentes no espaço dos significados". É o que afirma no ensaio "Sous l'horizon du langage" do livro homônimo:

Eu chamo de poesia aquilo que, no espaço das palavras, nosso mundo, possui memória dos referentes no espaço dos significados. E o que, face à grande pressão, não deixa de esquecer, deseja mesmo esquecer, substituindo a presença pelo imaginário, embora retorne à sua intuição em momentos imprevistos de sua constante inquietação. E são, então, não mais poemas mas furos no horizonte destes. Nada senão, às vezes, o início do ritmo, ou o encontro de algumas palavras: mas da luz, em seu instante de origem ${ }^{17}$.

Há no trecho citado uma proximidade entre memória e origem, espécie de mundo simbólico não fragmentado. É difícil não lembrar da reflexão de Heidegger, de uma poesia que "deixa habitar em sentido originário"18: poesia que promoveria um acesso ao não-esquecimento da unidade: em seus termos, desencobrimento/ "Unverborgenheit". Trata-se de uma vocação ontológica que a poesia de Yves Bonnefoy compartilharia com outros poetas franceses que publicaram a partir dos anos 1950, como Philippe Jaccottet, Lorand Gaspar, Jacques Dupin. Em Les

${ }_{17}$ BONNEFOY, 2002, p. 8 : “J'appelle poésie ce qui, dans l'espace des mots, notre monde, a mémoire du surcroît de ce qui est sur ses représentations: mémoire des référents dans l'espace des signifiés. Et ce qui, du fait de la grande contrainte, ne cesse pas d'oublier, même désire oublier, substituant imaginaire à présence, mais revient à son intuition à des moments imprévus de sa constante inquiétude. Et ce sont alors non pas vraiment les poèmes mais des trouées à l'horizon de ceux-ci. Rien parfois qu'un début de rythme, ou la rencontre de quelques mots: mais cela de la lumière, en son instant d'origine".

${ }^{18}$ HEIDEGGER, 1999, p. 257. 
planches courbes, contudo, trata-se de um mundo que emerge, igualmente, a partir da experiência autobiográfica - lírica e autobiográfica.É uma memória dos rumores, dos silêncios, no contato com uma alegria primeira, com um mundo de presenças plenas - a água, a terra, a pedra - , mas que advém de uma espécie de reconciliação consigo mesmo.Daí a possibilidade de o eu reatar-se com o passado, instituindo uma continuidade que culminaria no reconhecimento de si, na certeza dessa duração: "foi preciso que algo tenha permanecido desde a primeira impressão para que eu me lembre agora", diria Paul Ricoeur"19. O poeta não será mais, assim, o "eu" melancólico do ensaio "Les tombeaux de Ravenne", o "eu" em luta de Douve, mas um "eu" reconciliado,que endireita o galho "que se rompeu" no poema "Que ce monde demeure!" / "Que esse mundo permaneça", que cito a seguir, e com o qual concluo:

Je redresse une branche

Qui s'est rompue. Les feuilles

Sont lourdes d'eau et d'ombre

Comme ce ciel, d'encore

Avant le jour. Ô terre,

Signes désaccordés, chemins épars,

Mais beauté, absolue beauté,

Beauté de fleuve,

Que ce monde demeure,

Malgré la mort!

Serrée contra la branche

L'olive grise.

[Reergo um galho

Que se rompeu. As folhas

Estão pesadas de água e de sombra

Como o céu, de ainda

${ }^{19}$ RICOEUR, 2000, p. 557. 
Antes do dia. Ó terra,

Signos desafinados, caminhos esparsos,

Mas beleza, absoluta beleza,

Beleza de rio,

Que esse mundo permaneça,

Apesar da morte!

Cerrada contra o galho

A azeitona cinza. $]^{20}$

${ }^{20}$ BONNEFOY, 2001, p. 25. 


\section{Referências bibliográficas}

BONNEFOY, Yves. L'Improbable, suivi de Quatre Notes et de Un Rêve fait à Mantoue, nouvelle édition corrigée et augmentée. Paris: Idées / Gallimard, 1980.

. Poèmes: Anti-Platon (1947), Du Mouvement et de l'immobilité de Douve (1953), Hier régnant désert (1958), Pierre écrite (1965),Dans le leurre du seuil (1975). Paris: Gallimard, 1982.

. Les planches courbes. Paris: Mercure de France, Gallimard, 2001.

Sous l'horizon du langage. Paris: Mercure de France, 2002.

. Dictionnaire des mythologies et des religions des societés traditionnelles et du monde antique (org.). Paris: Flammarion, 1981/1999, 2 vols.

.Sous l'horizon du langage. Paris: Mercure de France, 2002.

HEIDEGGER, Martin. “Tempo e Ser". In Conferências e escritos filosóficos. Trad. Ernildo Stein. São Paulo: Nova Cultural, 1999.

LEUWERS, Daniel. Yves Bonnefoy. Amsterdam: Rodopi, 1988.

RICOEUR, Paul. La mémoire, l'histoire, l'oubli. Paris: Éditions du Seuil, 2000.

RUSSO, Adelaide.Le peintre comme modèle: du surréalisme à l'extrême contemporain.Lille: Presses universitaires du Septentrion, 2007. 


\section{Resumo}

Esta comunicação pretende percorrer alguns poemas de Les planches courbes (2001) de Yves Bonnefoy a partir da oposição memória/esquecimento. Tal reflexão está esboçada no ensaio "Sous l'horizon du langage" do livro homônimo, quando afirma que a poesia é "o que, no espaço das palavras, nosso mundo, guarda memória do acréscimo do que existe sobre suas representações". Trata-se de uma memória que se situaria menos a partir de um lugar perdido, do que reconquistado. É a ela que o "eu" se confia: no "sim", na paz, palavras que surgem nos livros mais recentes. O poeta traria uma confiança que retomaria, de certo modo, o que Paul Ricœur caracterizou como o sentido das inscriçõesafeições: "elas seriam depositárias da significação a mais dissimulada, a mais originária do verbo "demeurer", sinônimo de "durer". Em Les planches courbes, trata-se, igualmente, de uma memória da infância e dos mitos. São acontecimentos que passam a ter o seu lugar num tempo primordial. Esperança/confiança, portanto, de remontar a uma força mais antiga da língua, de si mesmo, do ser, de suas relações. A uma unidade no simples, fundindo a apreensão do mundo e do eu num ato de suficiência, em que este se conjuga com um tipo de despossessão: da ideia, do conceito, da imagem.

\section{Resumé:}

Cette communication prétend parcourir quelques poèmes de Les planches courbes (2001) d'Yves Bonnefoy à partir de l'opposition entre mémoire et oubli. Cette réflexion se trouve esquissée dans l'essai “Sous l'horizon du langage" du livre homonyme, lorsqu'il affirme que la poésie est "ce qui, dans l'espace des mots, notre monde, a mémoire du surcroît de ce qui est sur ses représentations" (2002 : 8). Il s'agit d'une mémoire établie moins à partir d'un lieu perdu que retrouvé. 
Ce à elle que le moi se confie: dans le "oui", dans la paix, ces deux mots qui apparaissent dans ses livres les plus récents. Le poète apporterait une confiance qui reprendrait, d'une certaine façon, ce que Paul Ricœur a caractérisé comme le sens des inscriptions-affections: "elles seraient le dépositaire de la signification la plus dissimulée, mais la plus originaire du verbe "demeurer", synonyme de "durer". Dans Les planches courbes, il s'agit également d'une mémoire de l'enfance et des mythes. Ce sont des événements qui prennent place dans un temps primordial. Espoir/confiance, donc, de remonter à une force plus ancienne de la langue, de soi-même, de l'être, de ses rapports. Remonter à une unité dans le simple, en reliant une appréhension du monde et de soi-même dans un acte de suffisance, dans lequel celui-ci se conjugue avec une espèce de dépossession: de l'idée, du concept, de l'image. 